\title{
Tofacitinib for induction of remission in ulcerative colitis: systematic review and meta-analysis
}

\author{
Paschalis Paschos ${ }^{a, b}$, Anastasia Katsoulaa,c, Olga Gioulemec, Maria Sarigiannia, Aris Liakos ${ }^{a}$, \\ Eleni Athanasiadou ${ }^{a}$, Eleni Bekiaria ${ }^{2}$, Apostolos Tsapas ${ }^{\mathrm{a}, \mathrm{d}}$
}

Aristotle University of Thessaloniki, Greece; Papageorgiou Hospital, Thessaloniki, Greece; University of Oxford, UK

\begin{abstract}
Background The aim of the study was to assess the efficacy and safety of tofacitinib and its impact on quality of life in patients with moderate-to-severe ulcerative colitis.

Methods We conducted a systematic review and meta-analysis of randomized controlled trials comparing tofacitinib with placebo or any active comparator. We searched Medline, Embase, the Cochrane Library and gray literature for articles published up to May 2017. We synthesized data using a fixed-effect model. We conducted subgroup analysis based on prior exposure to anti-tumor necrosis factor (TNF). We summarized the strength of evidence using the Grading of Recommendations Assessment, Development and Evaluation (GRADE) approach.
\end{abstract}

Results We included three trials with 1220 participants. Compared with placebo, tofacitinib was effective in inducing clinical remission (odds ratio [OR] 3.84, 95\% confidence interval [CI] 2.296.44, $I^{2:} 41 \%$, GRADE: moderate), clinical response (OR 2.95, 95\%CI 2.21-3.95, $I^{2:} 0 \%$, GRADE: high), mucosal healing (OR 2.70, 95\%CI 1.81-4.03, $I^{2:} 0 \%$, GRADE: high). Tofacitinib was effective in both anti-TNF-naïve and -experienced patients. Tofacitinib had a favorable effect on quality of life. There were no significant differences in the safety profile in terms of the incidence of any or serious adverse events compared to placebo. The risk for infections was increased (OR 1.51, 95\%CI 1.05-2.19, $I^{2:} 0 \%$, GRADE: moderate), but the incidence of serious infections did not differ between tofacitinib and placebo.

Conclusion In patients with moderate-to-severe ulcerative colitis, short-term treatment with tofacitinib is effective for induction of remission and improvement of quality of life.

Keywords Tofacitinib, ulcerative colitis, meta-analysis

Ann Gastroenterol 2018; 31 (4): 1-11

\begin{abstract}
${ }^{a}$ Clinical Research and Evidence-Based Medicine Unit, Second Medical Department, Aristotle University of Thessaloniki, Thessaloniki, Greece (Paschalis Paschos, Anastasia Katsoula, Maria Sarigianni, Aris Liakos, Eleni Athanasiadou, Eleni Bekiari, Apostolos Tsapas); 'First Department of Internal Medicine, "Papageorgiou" Hospital, Thessaloniki, Greece (Paschalis Paschos); 'Second Propaedeutic Department of Internal Medicine, Aristotle University of Thessaloniki, Thessaloniki, Greece (Olga Giouleme, Anastasia Katsoula); ${ }^{\mathrm{H}}$ Harris Manchester College, University of Oxford, Oxford, UK (Apostolos Tsapas)

Conflict of Interest: None

Correspondence to: Paschalis Paschos, MD, MSc, Clinical Research and Evidence-Based Medicine Unit, Second Medical Department, Hippokratio General Hospital, Aristotle University Thessaloniki, 49 Konstantinoupoleos Street, 54642 Thessaloniki, Greece, e-mail: pashospas@hotmail.com
\end{abstract}

Received 11 February 2018; accepted 24 March 2018; published online 10 May 2018

DOI: https://doi.org/10.20524/aog.2018.0276

\section{Introduction}

Ulcerative colitis (UC) is a lifelong inflammatory disease with a relapsing-remitting pattern $[1,2]$. The primary goal of treatment is to induce and maintain remission with as few adverse reactions as possible. Classic initial induction therapy includes corticosteroids or 5-aminosalicylic acid medications. In severe exacerbations and in those refractory or who do not respond to initial therapy, remission is induced and maintained with biologic agents $[3,4]$. At present, no pharmacological therapy can cure UC. Moreover, many patients are refractory or intolerant to current treatments [5]. Therefore, identification of new effective therapies is an important area of research.

Small-molecule agents are an emerging alternative to biological therapies for the treatment of UC. Tofacitinib is a novel orally administered small-molecule compound targeting Janus kinases (JAKs) that is being investigated as an immunosuppressive and anti-inflammatory agent for treating 
UC. Tofacitinib inhibits JAK 1 and JAK 3 , and to a lesser extent also JAK 2, modulating the signaling of interleukins $2,4,7$, 9,15 , and 21 [6]. As a result, tofacitinib blocks the activity of proinflammatory cytokines and the respective downstream cellular responses, hence leading to suppression of the immune response [7-9]. Based on the immune modulation, tofacitinib has been approved for treatment of rheumatoid arthritis $[10,11]$. Recently, well designed randomized controlled trials have suggested that tofacitinib has superior efficacy compared to placebo in patients with UC. To provide a thorough summary of the existing evidence concerning the efficacy and safety of tofacitinib, we conducted a systematic review and metaanalysis to assess the efficacy and safety of tofacitinib and its impact on health-related quality of life (HRQL).

\section{Materials and methods}

This review was based on a prespecified protocol and is reported in accordance with the Preferred Reporting Items for Systematic reviews and Meta-Analyses (PRISMA) statement [12].

\section{Study eligibility criteria}

We included all randomized controlled trials that compared tofacitinib with placebo or any active comparator in adults with active moderate-to-severe UC, irrespective of language, type, or date of publication. For the diagnosis of UC and assessment of disease activity, we accepted the definitions used by the authors of each trial.

\section{Identification and selection of studies}

We developed a search strategy using relevant keywords for tofacitinib and UC. Our comprehensive search included Medline and Embase (Supplementary material). We also searched the Cochrane Library, for any relevant systematic reviews, and the ClinicalTrials.gov website. We also searched abstracts from meetings of the European Crohn's and Colitis Organisation, United European Gastroenterology, the American Gastroenterology Association, and American College of Gastroenterology, from January 2010 to February 2017. Finally, we scanned the website of the manufacturing pharmaceutical company and perused the reference lists of relevant articles and reviews. The last search was performed in November 2016 and the search of electronic databases was updated in May 2017.

We imported all references from the electronic databases into reference management software (EndNote X7, Thomson Reuters, New York City, New York). Following deduplication, two reviewers independently screened titles and abstracts and subsequently examined the full text of potentially eligible reports. Eligible trials from gray literature sources were juxtaposed with the results from electronic databases. Any disagreement at each stage of the selection process was resolved through discussion.

\section{Data collection process}

Two reviewers (PP and $\mathrm{AK}$ ) independently extracted data from each eligible study and discrepancies were resolved through consultation with a senior reviewer (AT). We used a predefined data extraction form to collect information from relevant studies. We collated multiple reports for each trial. For each eligible trial, we extracted data on study characteristics, participants' baseline characteristics, and pre-specified outcomes.

\section{Risk of bias in individual studies}

Two authors (PP and EA) evaluated the risk of bias of each included study using the Cochrane Risk of Bias Tool [13]. Trials were classified as having a high, low or unclear risk of bias, with reference to each of the following domains: sequence generation, allocation concealment, blinding of participants and personnel, blinding of outcome assessors, incomplete outcome data, and selective reporting. We assessed the blinding of participants and personnel, blinding of outcome assessors and incomplete outcome data separately for efficacy and safety outcomes. Regarding incomplete outcome data, relatively low $(<20 \%)$ and balanced attrition rates between treatment arms, use of intention-to-treat analyses and appropriate imputation methods to handle missing data were deemed to represent a low risk of bias for this domain. Studies with adequate procedures in all domains were deemed to have a low risk of bias, while studies with inadequate procedures in at least one domain were deemed to have a high risk of bias. In all other cases, studies were deemed to have an unclear risk of bias.

\section{Outcome measures}

The primary outcome was clinical remission, as defined by the investigators of each individual study. Secondary efficacy outcomes were clinical response, mucosal healing, and symptomatic and endoscopic remission, as defined by the primary studies. Secondary outcomes that assessed the impact of tofacitinib on HRQL included the mean difference in the disease-specific Inflammatory Bowel Disease Questionnaire (IBDQ) and the generic Short Form 36-item questionnaire (SF-36), the proportion of patients achieving an increase in total IBDQ score of $\geq 16$ points from baseline (IBDQ response) and the proportion of patients with a total IBDQ score of $\geq 170$ points (IBDQ remission). Safety endpoints included the incidence of any adverse event (AE), incidence of serious AEs, discontinuation due to AEs, incidence of infections and incidence of serious infections.

Tofacitinib has not yet received regulatory approval and data for the most common dose (10 mg) were synthesized. 


\section{Data synthesis}

For dichotomous outcomes, we used the Mantel-Haenszel fixed effects formulae to calculate pooled odds ratios (ORs) and 95\% confidence intervals (CIs). We used an inverse variance weighted fixed effects model to calculate mean differences (MD) and 95\%CIs for continuous outcomes. When available, data for intention-to-treat populations were used. All analyses were performed at the 0.05 significance level. We quantified statistical heterogeneity using the $I^{2}$ statistic, with values greater than $50 \%$ representing considerable heterogeneity. We planned to assess publication bias for the primary outcome both visually, by checking the funnel plot for asymmetry, and formally using Egger's test [14]. All statistical analyses were performed using Review Manager 5.3 [15].

We conducted a predefined subgroup analysis, based on exposure to prior anti-tumor necrosis factor (TNF) therapy. Sensitivity analysis was also planned, including only trials with a low risk of bias.

\section{Grading of evidence}

We used the Grading of Recommendations Assessment, Development and Evaluation (GRADE) approach [16] to summarize the strength of evidence and determine the confidence in summary estimates for clinically relevant comparisons and outcomes. Two reviewers (PP and MS) graded inconsistency, risk of bias, indirectness, imprecision, and publication bias for evidence related to each of the following outcomes: remission, response, mucosal healing, incidence of $\mathrm{AE}$, discontinuation due to $\mathrm{AE}$, incidence of infections. We resolved any disagreements through discussion with a senior reviewer (AT). We used GRADEpro (GRADE Working Group) to produce a summary of findings Table.

\section{Results}

\section{Results of search and study characteristics}

The search process is summarized in the form of a PRISMA diagram in Fig. 1. Our search identified 221 records. After deduplication, we screened 192 titles and abstracts and rejected 155 records. We assessed the full text of the remaining 37 reports. Elevencitations, corresponding to one phase 2 and two phase 3 (OCTAVE Induction 1 and OCTAVE Induction 2) multicenter, randomized, placebo-controlled trials, met the inclusion criteria and were finally included in the metaanalysis [17-27].

The studies and the participants' baseline characteristics are summarized in Table 1. The studies recruited 1220 patients with active moderate-to-severe UC, with a Mayo score of 6-12 and an endoscopic subscore of at least 2, and previous treatment with mesalamine, corticosteroids, azathioprine/6mercaptopurine, or anti-TNF regimens. The patients' mean age ranged from 40.4-43.2 years and the proportion of men ranged from 48-64\%. All studies included patients with prior exposure to anti-TNF- $\alpha$ therapy (29-46.7\%). Oral mesalamine and oral corticosteroids at a stable dose were allowed as concomitant treatment. In the phase 2 trial [24], participants were randomly assigned to tofacitinib at a dose of $0.5 \mathrm{mg}$, $3 \mathrm{mg}, 10 \mathrm{mg}$ or $15 \mathrm{mg}$, or placebo twice daily for 8 weeks. In the phase 3 studies [23], patients were allocated to tofacitinib $10 \mathrm{mg}$ twice daily or placebo for eight weeks. All studies used the Mayo Clinic activity index to define disease severity and efficacy outcomes. Definitions of outcomes were consistent across trials.

\section{Risk of bias assessment}

The risk of bias assessment is summarized in Table 2 . Phase 3 studies [23] were methodologically rigorous with low attrition rates, ranging from $3.3-13.4 \%$, and were deemed to have a low risk of bias. The phase 2 study [24] was deemed to have a high risk of bias because of the high attrition rate $(27.1 \%)$ in the placebo arm.

\section{Analysis of main outcomes}

Clinical remission was defined based on a total Mayo score of $\leq 2$ points, and individual subscores $\leq 1$ point (OR 3.84, 95\%CI 2.29-6.44, $I^{2:} 41 \%$ ). Phase 3 trials [23] also used a more stringent definition of remission, with the additional requirement of a rectal bleeding subscore of 0 (OR 3.36, 95\%CI 1.90-5.92, $\left.I^{2}: 30 \%\right)$. Irrespective of the definition utilized, the proportion of patients achieving remission was significantly higher among patients treated with tofacitinib than in those receiving placebo. When data were analyzed separately based on prior exposure to anti-TNF, the OR was 2.20 (95\%CI 1.18$\left.4.10, I^{2:} 0 \%\right)$ for anti-TNF-naïve patients and 12.15 (95\%CI 2.38-62.07, $I^{2: 0 \%)}$ for anti-TNF-experienced patients (Table 3). A GRADE analysis indicated that the quality of the evidence supporting clinical remission was moderate because of sparse data (Table 4).

Clinical response was defined based on a change in Mayo score from baseline of at least three points and at least 30\%, with an accompanying decrease in the rectal bleeding subscore of at least one point or an absolute rectal bleeding subscore of $\leq 1$. Tofacitinib was associated with higher response rates compared to placebo (OR 2.95, 95\%CI 2.21-3.95, $I^{2:} 0 \%$ ). In a subgroup analysis, both anti-TNF-naïve and -experienced participants had a higher rate of response (OR 2.32, 95\%CI 1.57-3.43, $I^{2:} 0 \%$ and OR 3.43, 95\%CI 2.25-5.22, $I^{2:} 48 \%$, respectively) (Table 3 ). The quality of evidence regarding the clinical response was high (Table 4).

Only phase 3 studies $(n=1139)$ reported data on mucosal healing, defined as a Mayo endoscopic subscore of $\leq 1$. Tofacitinib was associated with increased rates of mucosal healing (OR 2.70, 95\%CI 1.87-4.16, $I^{2:} 0 \%$ ). In anti-TNFnaive patients, the OR was 2.06 (95\%CI $\left.1.81-4.03, I^{2:} 0 \%\right)$ and 


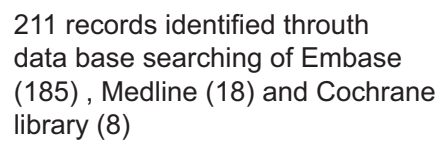

21 additional records identified from conference abstracts (17) and Clinical trals.gov (4)

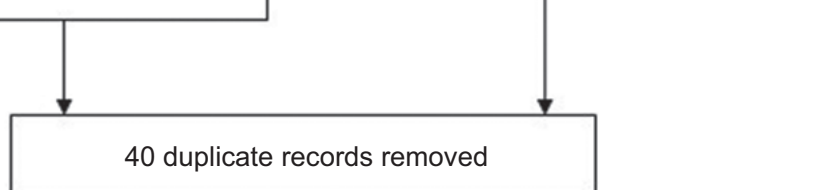

192 records screened

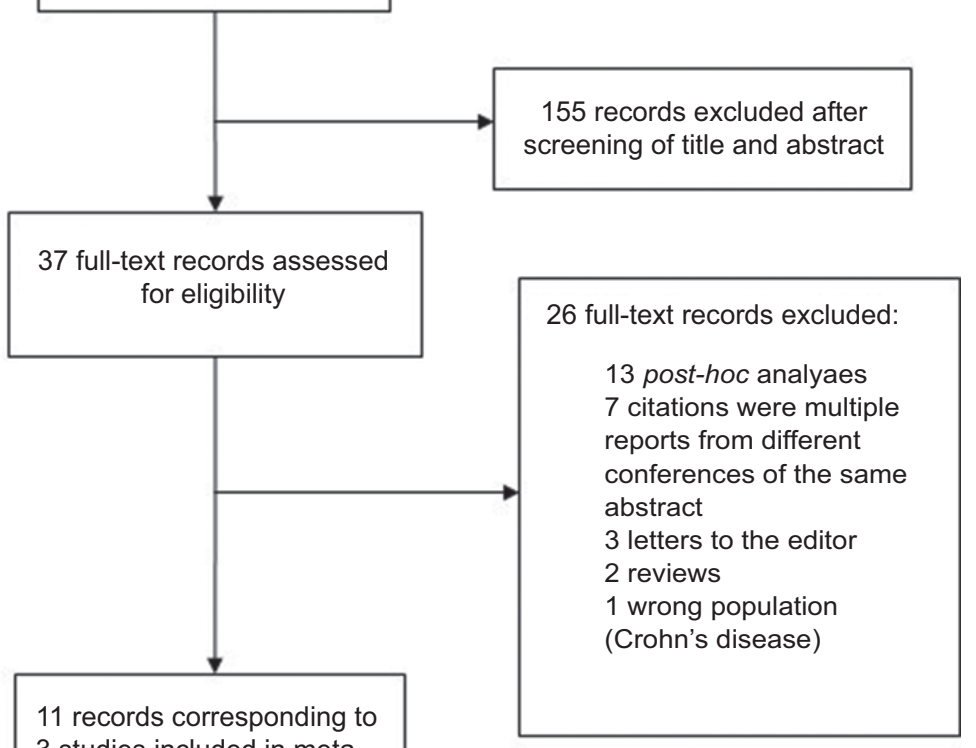

3 studies included in metaanalysis

Figure 1 Flow diagram

in anti-TNF-experienced patients the OR was 4.53 (95\%CI 2.15-9.56, $\left.I^{2:} 0 \%\right)$. The quality of evidence regarding mucosal healing was high (Table 4 ).

The proportion of tofacitinib-treated participants who had a normal endoscopic appearance (endoscopic remission defined as Mayo endoscopic subscore of 0 ) was greater compared with that for placebo (OR 5.65, 95\%CI 2.25-14.17, $I^{2:} 0 \%$ ). Finally, rates of symptomatic remission (defined as clinical remission with 0 subscore for both rectal bleeding and stool frequency) were higher in the tofacitinib than in the placebo group (OR $2.85,95 \%$ CI $\left.1.46-5.54, I^{2:} 0 \%\right)$. The results for efficacy outcomes are presented in Fig. 2.

Three studies $(\mathrm{n}=1217)$ reported mean IBDQ scores at week 8 among patients who received tofacitinib $(n=936)$ or placebo $(n=281)$. The mean IBDQ score was significantly better among tofacitinib patients compared to those receiving placebo (MD 13.30, 95\%CI 9.70-16.90, I: 0\%). A higher proportion of tofacitinib patients achieved an IBDQ response (OR 2.06, 95\%CI 1.56-2.72, $I^{2:} 0 \%$ ) and IBDQ remission (OR
2.66, 95\%CI 1.94-3.65, $I^{2: 31 \%) ~ c o m p a r e d ~ t o ~ t h e ~ p l a c e b o ~}$ group. There was statistically significant superiority in the mean SF-36 Physical Component Summary (MD 3.45, 95\%CI 2.44-4.45, $I^{2:}$ 75\%) and Mental Component Summary (MD 3.94, 95\%CI 2.69-5.19, $I^{2:} 0 \%$ ) among tofacitinib patients compared to those receiving placebo. The HRQL outcomes are presented in Fig. 3.

Analysis revealed no significant differences in the safety profile in terms of the incidence of any or serious adverse events for tofacitinib compared to placebo (OR 0.93, 95\%CI $0.68-1.28, I^{2:} 0 \%$ and OR $0.63,95 \%$ CI $0.34-1.15, I^{2:} 0 \%$, respectively). Withdrawals due to adverse events were similar between tofacitinib and placebo (OR 0.94, 95\%CI 0.34-2.60, $I^{2:} 0 \%$ ). The most common reason that led to discontinuation was worsening of UC. There was a marginally higher incidence of infections (OR 1.51, 95\%CI 1.05-2.19, $I^{2:} 0 \%$ ). The incidence of serious infections did not differ between tofacitinib and placebo (OR 3.17, 95\%CI 0.56-17.94, $I^{2:} 0 \%$ ), but very few cases of serious infection were reported in 
Table 1 Studies and participants' baseline characteristics

\begin{tabular}{|c|c|c|c|c|c|c|c|c|c|}
\hline $\begin{array}{l}\text { Study } \\
\text { (NCT } \\
\text { number) }\end{array}$ & Interventions & $\begin{array}{c}\text { Number } \\
\text { of } \\
\text { patients }\end{array}$ & $\begin{array}{l}\text { Age, } \\
\text { years }\end{array}$ & $\begin{array}{c}\text { Males, } \\
\%\end{array}$ & $\begin{array}{c}\text { Disease } \\
\text { duration, } \\
\text { years }\end{array}$ & $\begin{array}{c}\text { Disease } \\
\text { severity, } \\
\text { Mayo } \\
\text { score }\end{array}$ & $\begin{array}{c}\% \text { of } \\
\text { patients } \\
\text { with } \\
\text { extensive } \\
\text { colitis/ } \\
\text { Pancolitis } \\
\text { at } \\
\text { baseline }\end{array}$ & $\begin{array}{l}\% \text { of } \\
\text { anti- } \\
\text { TNF } \\
\text { naïve } \\
\text { patients }\end{array}$ & $\begin{array}{l}\% \text { of } \\
\text { patients with } \\
\text { concomitant } \\
\text { treatment with } \\
\text { corticosteroids }\end{array}$ \\
\hline $\begin{array}{l}\text { Sandborn } \\
2012 \\
(00787202) \\
{[24]}\end{array}$ & $\begin{array}{l}\text { Tofacitinib } \\
10 \mathrm{mg} \\
\text { Placebo }\end{array}$ & $\begin{array}{l}33 \\
48\end{array}$ & $\begin{array}{l}43.2 \pm 12.8 \\
42.5 \pm 14.7\end{array}$ & $\begin{array}{l}64 \\
48\end{array}$ & $\begin{array}{l}10.9 \pm 6.6 \\
8.87 \pm 5.4\end{array}$ & $\begin{array}{c}8 \pm 1.7 \\
8.2 \pm 1.6\end{array}$ & $\begin{array}{l}42 \\
43\end{array}$ & $\begin{array}{l}70 \\
69\end{array}$ & $\begin{array}{l}58 \\
27\end{array}$ \\
\hline $\begin{array}{l}\text { OCTAVE } \\
1 \\
(01465763) \\
{[23]}\end{array}$ & $\begin{array}{l}\text { Tofacitinib } \\
10 \mathrm{mg} \\
\text { Placebo }\end{array}$ & $\begin{array}{l}476 \\
122\end{array}$ & $\begin{array}{l}41.3 \pm 14.1 \\
41.8 \pm 15.3\end{array}$ & $\begin{array}{l}58 \\
63\end{array}$ & $\begin{array}{c}6.5(0.3- \\
42.5) \\
6(0.5- \\
36.2)\end{array}$ & $\begin{array}{l}9.0 \pm 1.4 \\
9.1 \pm 1.4\end{array}$ & $\begin{array}{l}53.1 \\
54.1\end{array}$ & $\begin{array}{l}53.4 \\
53.3\end{array}$ & $\begin{array}{c}45 \\
47.5\end{array}$ \\
\hline $\begin{array}{l}\text { OCTAVE } \\
2 \\
(01458951) \\
{[23]}\end{array}$ & $\begin{array}{l}\text { Tofacitinib } \\
10 \mathrm{mg} \\
\text { Placebo }\end{array}$ & $\begin{array}{l}429 \\
112\end{array}$ & $\begin{array}{l}41.1 \pm 13.5 \\
40.4 \pm 13.2\end{array}$ & $\begin{array}{l}60 \\
49\end{array}$ & $\begin{array}{c}6(0.4- \\
39.4) \\
6.2(0.4- \\
27.9)\end{array}$ & $\begin{array}{l}9.0 \pm 1.5 \\
8.9 \pm 1.5\end{array}$ & $\begin{array}{l}49.3 \\
50.5\end{array}$ & $\begin{array}{c}54.5 \\
58\end{array}$ & $\begin{array}{l}46.2 \\
49.1\end{array}$ \\
\hline
\end{tabular}

Data are mean \pm SD or median (range) unless otherwise indicated

NCT, ClinicalTrials.gov registry number; TNF, tumor necrosis factor

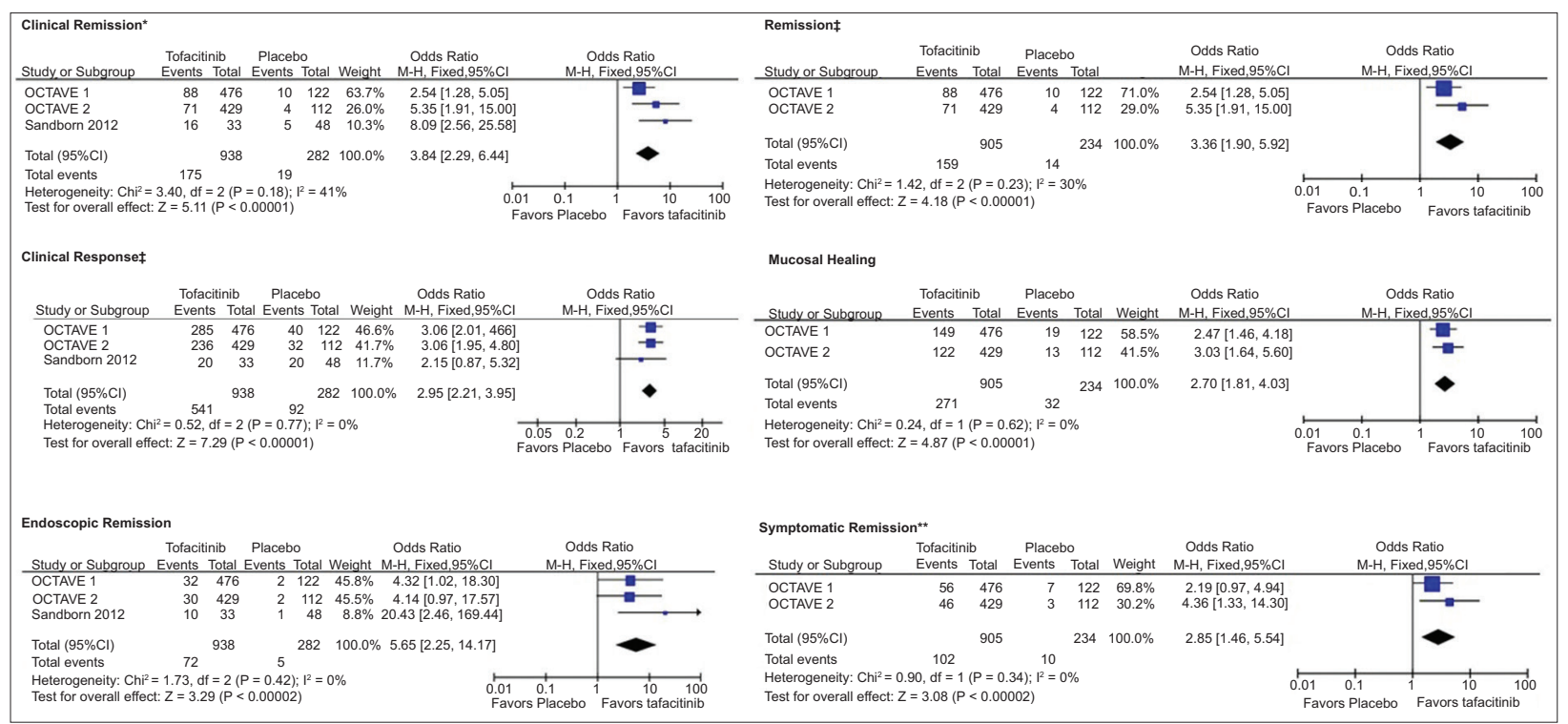

Figure 2 Meta-analytic findings for efficacy outcomes

${ }^{*}$ Clinical Remission: Total Mayo score $\leq 2$, with individual subscores $\leq 1$ point, $\dagger$ Remission: Total Mayo score $\leq 2$ points, with individual subscores $\leq 1$ point and a rectal bleeding subscore of 0 , $\ddagger$ Clinical Response: Decrease from induction study baseline in Mayo score of at least 3 points and at least $30 \%$, with an accompanying decrease in the rectal bleeding subscore of at least 1 point or absolute rectal bleeding subscore of 0 or $1, \S \mathrm{Mucosal}$ healing: Endoscopic subscore $\leq 1$, 9 Endoscopic remission: Endoscopic subscore of 0 , ${ }^{*}$ Symptomatic remission: Total Mayo score $\leq 2$ points, with individual subscore $\leq 1$ point, and both rectal bleeding and stool frequency subscore of 0

M-H, Mantel-Haenszel; CI, confidence interval

the trials. Only one death was reported in the tofacitinib group during trials; this was due to aortic dissection and was assessed as unrelated to the study drug. The quality of evidence concerning the incidence of any adverse event was high (Table 4), but the quality was low for the incidence of infections and for withdrawals due to adverse events, because of the sparse data. The safety outcome data are presented in Table 5.

We could not perform a sensitivity analysis based on the risk of bias because of the small number of studies. 
Table 2 Risk of bias assessment for included studies

\begin{tabular}{|c|c|c|c|c|c|c|c|c|c|c|}
\hline \multirow[t]{2}{*}{ Study } & \multirow[t]{2}{*}{$\begin{array}{l}\text { Sequence } \\
\text { generation }\end{array}$} & \multirow[t]{2}{*}{$\begin{array}{l}\text { Allocation } \\
\text { concealment }\end{array}$} & \multicolumn{2}{|c|}{$\begin{array}{l}\text { Blinding of } \\
\text { participants/personnel }\end{array}$} & \multicolumn{2}{|c|}{$\begin{array}{l}\text { Blinding of outcome } \\
\text { assessors }\end{array}$} & \multicolumn{2}{|c|}{$\begin{array}{l}\text { Incomplete outcome } \\
\text { data }\end{array}$} & \multirow{2}{*}{$\begin{array}{l}\text { Selective } \\
\text { outcome } \\
\text {-reporting }\end{array}$} & \multirow[t]{2}{*}{ Overall } \\
\hline & & & $\begin{array}{l}\text { Efficacy } \\
\text { outcomes }\end{array}$ & $\begin{array}{l}\text { Safety } \\
\text { outcomes }\end{array}$ & $\begin{array}{l}\text { Efficacy } \\
\text { outcomes }\end{array}$ & $\begin{array}{l}\text { Safety } \\
\text { outcomes }\end{array}$ & $\begin{array}{l}\text { Efficacy } \\
\text { outcomes }\end{array}$ & $\begin{array}{l}\text { Safety } \\
\text { outcomes }\end{array}$ & & \\
\hline $\begin{array}{l}\text { Sandborn } \\
2012[24]\end{array}$ & Low & Low & Low & Low & Unclear & Low & High & High & Low & High \\
\hline $\begin{array}{l}\text { OCTAVE } 1 \\
{[23]}\end{array}$ & Low & Low & Low & Low & Low & Low & Low & Low & Low & Low \\
\hline $\begin{array}{l}\text { OCTAVE } 2 \\
\text { [23] }\end{array}$ & Low & Low & Low & Low & Low & Low & Low & Low & Low & Low \\
\hline
\end{tabular}

Table 3 Subgroup analysis based on prior anti-TNF exposure

\begin{tabular}{|c|c|c|c|c|c|c|c|}
\hline \multirow[t]{2}{*}{ Outcome } & \multirow[t]{2}{*}{ Subgroup } & \multirow[t]{2}{*}{ Number of studies } & \multicolumn{2}{|c|}{ Tofacitinib } & \multicolumn{2}{|c|}{ Placebo } & \multirow[t]{2}{*}{ Odds ratio, $95 \% \mathrm{CI}, \mathrm{I}^{2}$} \\
\hline & & & Events & Total & Events & Total & \\
\hline \multirow{2}{*}{$\begin{array}{l}\text { Clinical } \\
\text { Remission* }\end{array}$} & Anti-TNF naïve & 2 & 99 & 417 & 13 & 104 & $2.20,1.18-4.10,0 \%$ \\
\hline & Anti-TNF experienced & 2 & 60 & 488 & 1 & 130 & $12.15,2.38-62.07,0 \%$ \\
\hline \multirow{2}{*}{$\begin{array}{l}\text { Clinical } \\
\text { Response }^{\dagger}\end{array}$} & Anti-TNF naïve & 3 & 328 & 512 & 57 & 131 & $2.32,1.57-3.43,0 \%$ \\
\hline & Anti-TNF experienced & 3 & 272 & 526 & 34 & 143 & $3.43,2.25-5.22,48 \%$ \\
\hline \multirow{2}{*}{$\begin{array}{l}\text { Mucosal } \\
\text { healing }^{\ddagger}\end{array}$} & Anti-TNF naïve & 2 & 159 & 417 & 24 & 104 & $2.06,1.25-3.40,0 \%$ \\
\hline & Anti-TNF experienced & 2 & 112 & 488 & 8 & 130 & $4.53,2.15-9.56,0 \%$ \\
\hline
\end{tabular}

${ }^{\star}$ Clinical remission: Total Mayo score of $\leq 2$ points, with individual subscores $\leq 1$ point and a rectal bleeding subscore of 0

${ }^{\dagger}$ Clinical response: Decrease from induction study baseline in Mayo score of at least 3 points and at least $30 \%$, with an accompanying decrease in the rectal bleeding subscore of at least 1 point or an absolute rectal bleeding subscore $\leq 1$

${ }^{\ddagger}$ Mucosal healing: Endoscopic subscore $\leq 1$

CI, confidence interval; TNF, tumor necrosis factor

\section{Discussion}

In our meta-analysis, moderate-to-high quality evidence supported the efficacy of tofacitinib for all outcomes, regardless of any prior treatment with an anti-TNF inhibitor. Tofacitinib had a favorable effect on the resolution of rectal bleeding and normalization of bowel habits, and it was superior to placebo in achieving normal endoscopic appearance at the end of the induction phase. An improvement in quality of life was also noted in tofacitinib treated patients compared with placebo groups. Finally, short-term treatment with tofacitinib was well tolerated, but low quality evidence suggested a marginally increased incidence of infections.

To our knowledge, this is the first systematic review and meta-analysis of the use of tofacitinib to treat UC. To ensure the internal validity of our conclusions, we implemented current guidelines for the conduct and reporting of systematic reviews. To reduce potential bias in the review process, we undertook a comprehensive search of multiple electronic databases and gray literature sources without imposing any restrictions. We rated the overall strength of evidence using the GRADE approach. All analyses demonstrated a low degree of heterogeneity and the trials were homogenous in terms of study design, outcome definitions and patient characteristics. In addition, the studies were methodologically rigorous and endoscopic appearance was assessed centrally, eliminating potential detection bias and discrepancies among assessors.

However, several limitations should also be acknowledged, at both the evidence and the review level. Only three placebocontrolled trials were included and we did not identify any head-to-head trials comparing tofacitinib with other licensed agents for UC. Since all studies received industry funding, the possibility of sponsorship bias cannot be excluded. The short follow up in all trials limits the validity of the results, especially with respect to safety. Moreover, the subgroup analysis based on prior anti-TNF exposure was an analysis of subgroups within studies; hence, randomization was "broken" and the results should be interpreted with caution. The limited number of studies precluded publication bias assessment.

Consistently beneficial results for all clinically meaningful outcomes, even when stringent definitions of outcomes were used, suggest that tofacitinib could be an effective new class of therapy targeting treatment-refractory patients, in accordance with the recently updated European Crohn's and Colitis Organisation guidelines [28]. Eight-week treatment induced mucosal healing, which has been associated with a reduced risk of relapse, avoidance of colectomy and corticosteroid-free remission [29,30]. In addition, tofacitinib seems to have effects 


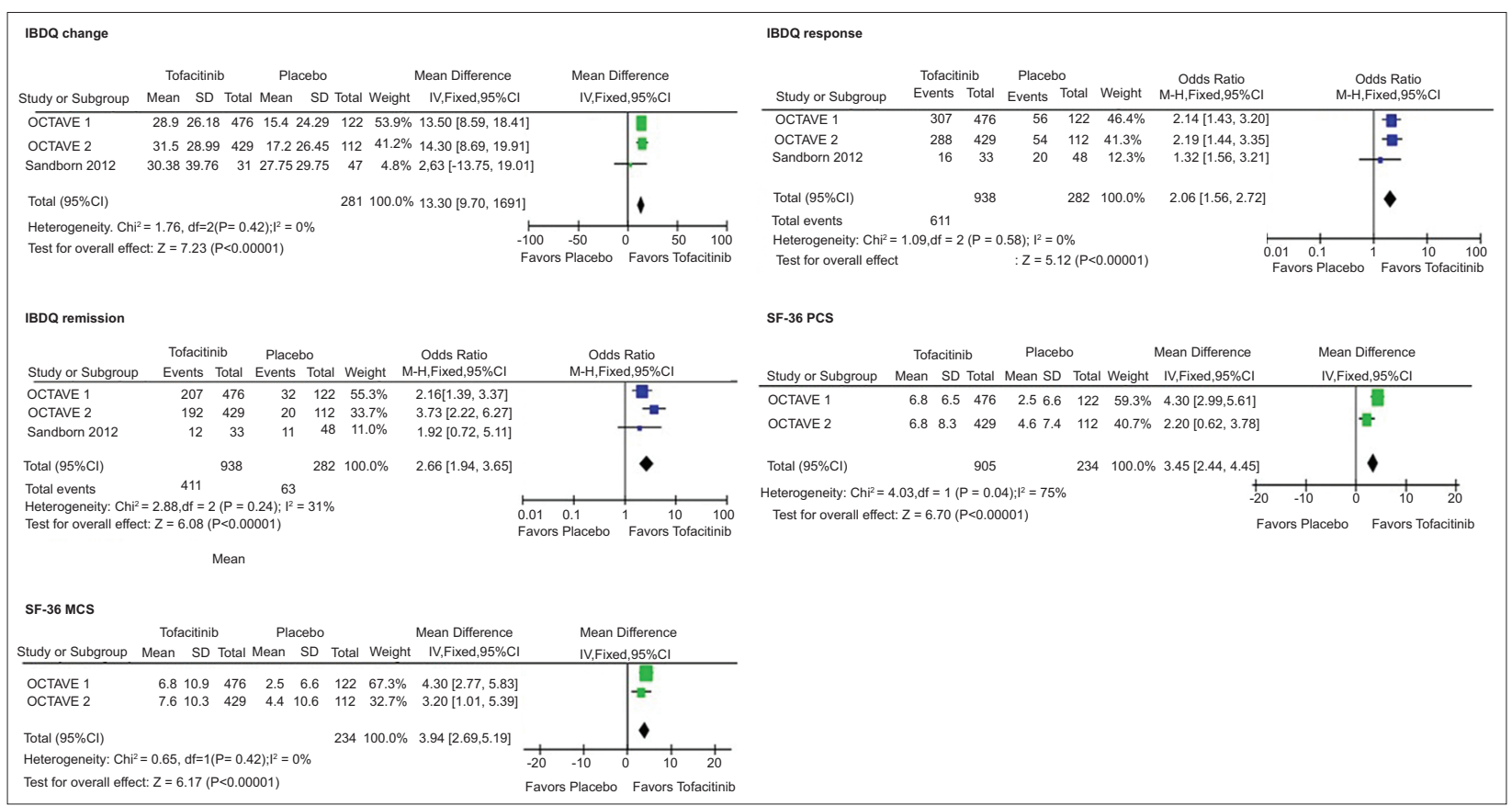

Figure 3 Meta-analytic findings for health-related quality of life outcomes

IBDQ, Inflammatory Bowel Disease Questionnaire; SD, standard deviation; IV, inverse variance; CI, confidence interval; M-H, Mantel-Haenszel; SF36 PCS, Short Form-36 Physical Component Summary; SF-36 MCS, Short Form-36 Mental Component Summary

on mucosal healing comparable to those of other licensed pharmacological interventions [31,32]. Notably, the beneficial effects of tofacitinib were more pronounced in patients previously treated with anti-TNF regimens, regarded as a population more difficult to treat than anti-TNF-naïve patients. However, estimates should be interpreted with caution because trials were not designed to detect these subgroup differences and the estimates of remission are imprecise. Only two other trials, GEMINI 1 [33,34] with vedolizumab and ULTRA 2 [35] with adalimumab, recruited patients who had prior exposure to anti-TNF therapy. Indirect comparison through network meta-analysis of these three agents showed that tofacitinib is the most efficacious in patients with prior anti-TNF exposure [31]. Although tofacitinib improved the quality of life results, the change in mean IBDQ score may not be clinically meaningful ( $>16$ points), as the mean difference between tofacitinib and placebo was approximately 13 points. However, maintenance therapy resulted in a greater and clinically meaningful improvement in mean IBDQ score $(20.8,95 \% \mathrm{CI}$ 14.2-27.3) [36]. Overall, our results suggest that tofacitinib induces both symptomatic and endoscopic remission, the composite therapeutic target established by the international consensus on Selecting Therapeutic Targets in Inflammatory Bowel Disease (STRIDE) [37].

In the present meta-analysis, tofacitinib showed an acceptable safety profile, similar to the profile reported by randomized trials in rheumatoid arthritis [38,39]. Owing to its immune modulating effects, tofacitinib has been associated with an increased risk of infections. Long-term extension studies in patients with rheumatoid arthritis demonstrated an increased number of infections and especially higher rates of herpes zoster [39-41]. However, evidence from metaanalyses indicated that the overall risk of infection in patients with rheumatoid arthritis treated with tofacitinib appears to be comparable to the risk observed in patients treated with biologic agents $[42,43]$. In our analysis, the rate of infections was higher with tofacitinib, with nasopharyngitis being the most common infection. Serious infections occurred only in tofacitinib treated patients. However, the short followup duration and the scarcity of data concerning serious or opportunistic infections such as herpes zoster prompt further investigation. In a maintenance trial, the incidence of infections was also significantly higher for tofacitinib but no difference was noted in the incidence of serious infections [23].

Besides its efficacy and tolerability, tofacitinib is an orally administered agent and hence has an inherent advantage over parenterally administered biologic agents. In the CHOOSE trial, the convenience and time required for therapy influenced the patients' selection of a specific anti-TNF drug [44], potentially affecting the adherence to treatment.

There is an unmet need for long-term studies to draw safer inferences about the safety profile of tofacitinib. An ongoing, long-term extension study (NCT01470612) is anticipated to clear up current uncertainty from initial randomized trials [45]. Although recent methodologically rigorous network meta-analyses [31,32] have provided indirect evidence on comparative efficacy and safety, it is also imperative to conduct head-to-head comparisons with current treatment options and to determine the position of tofacitinib in the treatment algorithm for UC. Future studies are warranted to explore the potential benefit and risk of combining tofacitinib with other drugs, since combination therapy could be more effective than 


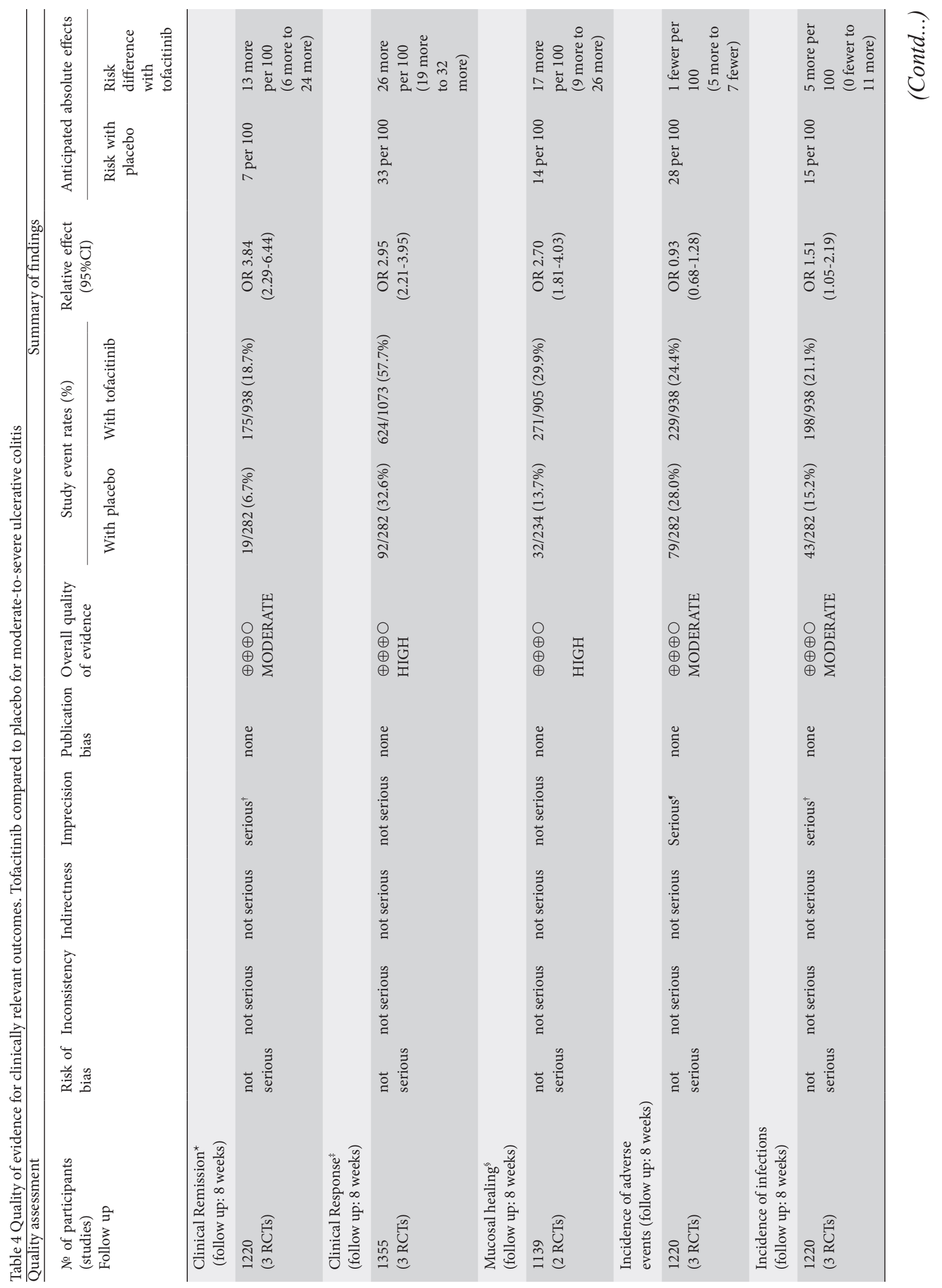


Tofacitinib for ulcerative colitis 9
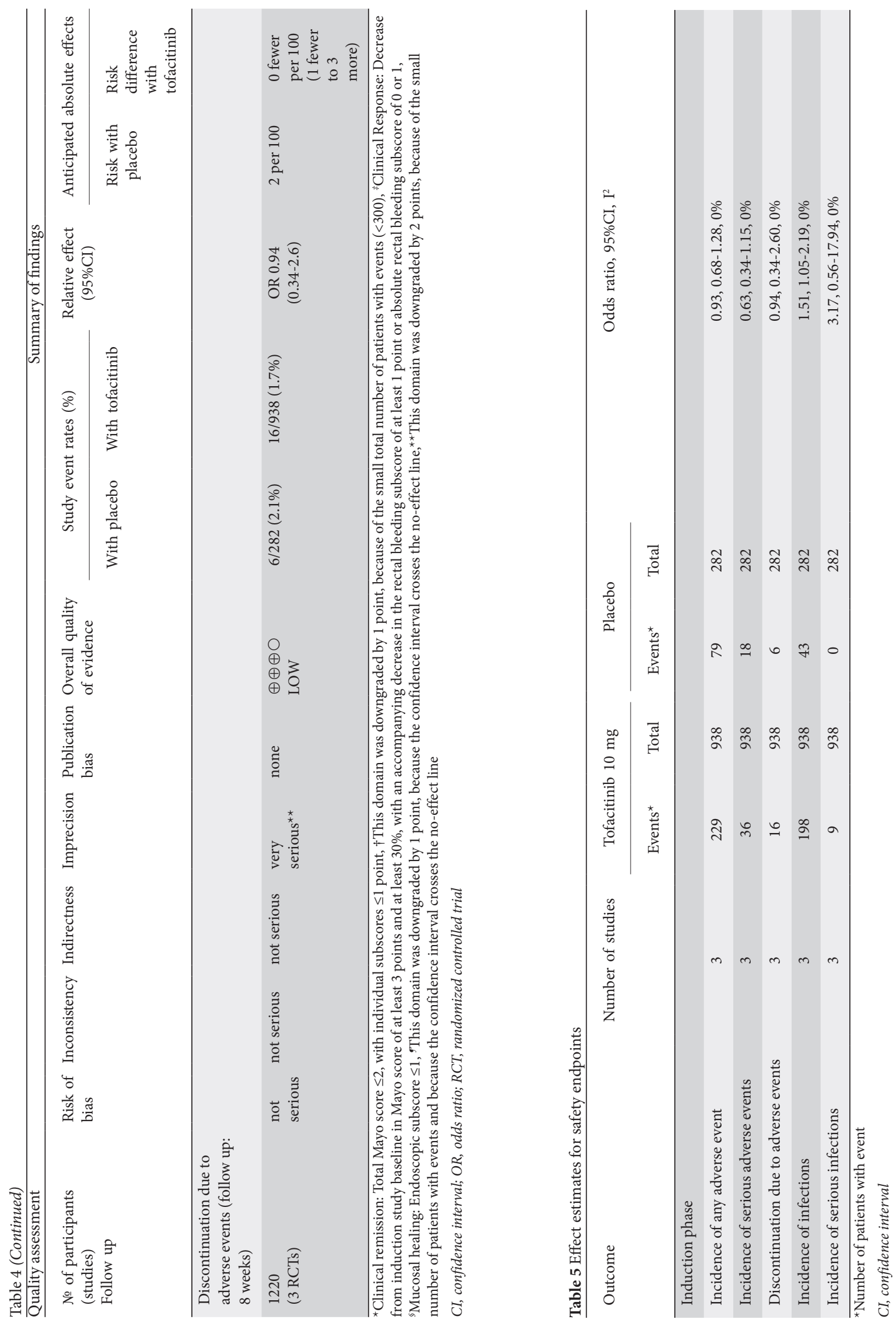
monotherapy while having an acceptable safety profile [46]. It is also crucial to identify the specific subsets of patients who are most likely to benefit from this new therapy. Finally, costeffectiveness analyses are also required, to properly inform the therapeutic decision-making process.

In conclusion, tofacitinib is effective in inducing remission in patients with moderate-to-severe active UC. Its convenience of administration, acceptable tolerability profile and favorable effect on important patient outcomes support its use. Further research is warranted to assess its long-term efficacy and safety profile.

\section{Summary Box}

\section{What is already known:}

- Tofacitinib is a novel treatment option for ulcerative colitis (UC) pending review by regulatory authorities

- It is the first orally administered therapy

- Randomized controlled trials have reported data on the efficacy and safety of tofacitinib

\section{What the new findings are:}

- High-to-moderate quality evidence indicates that short-term treatment with tofacitinib is effective in induction of remission in moderate-to-severe UC

- Tofacitinib has acceptable tolerability and an adequate safety profile

- Tofacitinib improves quality of life

\section{References}

1. Dignass A, Eliakim R, Magro F, et al. Second European evidencebased consensus on the diagnosis and management of ulcerative colitis part 1: definitions and diagnosis. J Crohns Colitis 2012;6:965-990.

2. Magro F, Gionchetti P, Eliakim R, et al. European Crohn's and Colitis Organisation [ECCO]. Third European evidence-based consensus on diagnosis and management of ulcerative colitis. part 1: definitions, diagnosis, extra-intestinal manifestations, pregnancy, cancer surveillance, surgery, and ileo-anal pouch disorders. J Crohns Colitis 2017;11:649-670.

3. Akiho H, Yokoyama A, Abe S, et al. Promising biological therapies for ulcerative colitis: a review of the literature. World J Gastrointest Pathophysiol 2015;6:219-227.

4. Dignass A, Lindsay JO, Sturm A, et al. Second European evidence-based consensus on the diagnosis and management of ulcerative colitis part 2: current management. J Crohns Colitis 2012;6:991-1030.

5. Mehta SJ, Silver AR, Lindsay JO. Review article: strategies for the management of chronic unremitting ulcerative colitis. Aliment Pharmacol Ther 2013;38:77-97.

6. Izzo R, Bevivino G, Monteleone G. Tofacitinib for the treatment of ulcerative colitis. Expert Opin Investig Drugs 2016;25:991-997.

7. Park SC, Jeen YT. Current and emerging biologics for ulcerative colitis. Gut Liver 2015;9:18-27.

8. Coskun M, Salem M, Pedersen J, Nielsen OH. Involvement of JAK/ STAT signaling in the pathogenesis of inflammatory bowel disease. Pharmacol Res 2013;76:1-8.

9. Boland BS, Sandborn WJ, Chang JT. Update on Janus kinase antagonists in inflammatory bowel disease. Gastroenterol Clin North Am 2014;43:603-617.

10. Gaujoux-Viala C, Nam J, Ramiro S, et al. Efficacy of conventional synthetic disease-modifying antirheumatic drugs, glucocorticoids and tofacitinib: a systematic literature review informing the 2013 update of the EULAR recommendations for management of rheumatoid arthritis. Ann Rheum Dis 2014;73:510-515.

11. Smolen JS, Landewé R, Breedveld FC, et al. EULAR recommendations for the management of rheumatoid arthritis with synthetic and biological disease-modifying antirheumatic drugs: 2013 update. Ann Rheum Dis 2014;73:492-509.

12. Moher D, Liberati A, Tetzlaff J, Altman DG; PRISMA Group. Preferred reporting items for systematic reviews and metaanalyses: the PRISMA statement. Int J Surg 2010;8:336-341.

13. Higgins JPT AD, Sterne JAC. Chapter 8: Assessing risk of bias in included studies. Cochrane Handbook for Systematic Reviews of Interventions Version 5.1.0 (updated March 2011). The Cochrane Collaboration. Available from: http://training.cochrane.org/ handbook

14. Egger M, Davey Smith G, Schneider M, Minder C. Bias in metaanalysis detected by a simple, graphical test. BMJ 1997;315:629-634.

15. Review Manager (RevMan). Version 5.3 ed. Copenhagen: The Nordic Cochrane Centre, The Cochrane Collaboration; 2014.

16. Schünemann H, Brożek J, Guyatt G, Oxman A. GRADE handbook for grading quality of evidence and strength of recommendations (Updated October 2013). The GRADE Working Group, 2013. Available from: https://gdt.gradepro.org/app/handbook/ handbook.html

17. D’Haens G, Sands BE, Sandborn WJ, et al. Tofacitinib has induction efficacy in moderately to severely active ulcerative colitis, regardless of prior TNF inhibitor therapy. United European Gastroenterol J 2016;4:A45.

18. Panés J, Su C, Marren A, et al. Improvement in patient-reported outcomes in 2 Phase 3 studies of tofacitinib in patients with moderately to severely active ulcerative colitis. J Crohns Colitis 2016;10:S283-S284.

19. Sandborn WJ, Danese S, Panés J, et al. Onset of efficacy of tofacitinib for induction therapy in patients with active ulcerative colitis in two multinational, phase 3 clinical trials. United European Gastroenterol J 2016;4:A441.

20. Sandborn WJ, Sands BE, D'Haens GR, et al. Efficacy and safety of oral tofacitinib as induction therapy in patients with moderate to severe ulcerative colitis: results from 2 Phase 3 randomized controlled trials. Gastroenterology 2016;150(Suppl 1):S157.

21. Panes J, Su C, Bushmakin AG, Cappelleri JC, Mamolo C, Healey P. Tofacitinib in active ulcerative colitis: analysis of efficacy based on patient-reported outcomes. J Crohns Colitis 2014;8(Suppl 1):S51.

22. Panés J, Su C, Bushmakin AG, Cappelleri JC, Mamolo C, Healey P. Randomized trial of tofacitinib in active ulcerative colitis: analysis of efficacy based on patient-reported outcomes. BMC Gastroenterol 2015;15:14.

23. Sandborn WJ, Su C, Sands BE, et al. OCTAVE Induction 1, OCTAVE Induction 2, and OCTAVE Sustain Investigators. Tofacitinib as induction and maintenance therapy for ulcerative colitis. N Engl J Med 2017;376:1723-1736.

24. Sandborn WJ, Ghosh S, Panes J, et al. Study A3921063 Investigators. Tofacitinib, an oral Janus kinase inhibitor, in active ulcerative colitis. N Engl J Med 2012;367:616-624.

25. Pfizer. A multicentre, randomized, double-blind, placebocontrolled, parallel-group study of oral CP-690,550 as an induction therapy in subjects with moderate to severe ulcerative colitis, 
2016. Available from: http://www.pfizer.com/sites/default/files/ clinical\%20trials/csr\%20synopsis/A3921095\%20Public\%20 Disclosure\%20Synopsis.pdf [Accessed April 17, 2018].

26. Pfizer. A multicentre, randomized, double-blind, placebocontrolled, parallel-group study of oral CP-690,550 as an induction therapy in subjects with moderate to severe ulcerative colitis, 2016. Available from: http://www.pfizer.com/sites/default/files/ clinical\%20trials/csr\%20synopsis/A3921094\%20Public\%20 Disclosure\%20Synopsis.pdf [Accessed April 17, 2018].

27. Pfizer. A multicentre, randomized, double-blind, placebocontrolled, parallel-group study of oral CP-690,550 as an induction therapy in subjects with moderate to severe ulcerative colitis, 2014. Available from: http://www.pfizer.com/sites/default/ files/clinical\%20trials/csr\%20synopsis/A3921063-Public\%20 Disclosure\%20Synopsis\%20.pdf [Accessed April 17, 2018].

28. Harbord M, Eliakim R, Bettenworth D, et al. European Crohn's and Colitis Organisation [ECCO]. Third European evidence-based consensus on diagnosis and management of ulcerative colitis. part 2: current management. J Crohns Colitis 2017;11:769-784.

29. Shah SC, Colombel JF, Sands BE, Narula N. Mucosal healing is associated with improved long-term outcomes of patients with ulcerative colitis: a systematic review and meta-analysis. Clin Gastroenterol Hepatol 2016;14:1245-1255.

30. Colombel JF, Rutgeerts P, Reinisch W, et al. Early mucosal healing with infliximab is associated with improved longterm clinical outcomes in ulcerative colitis. Gastroenterology 2011;141:1194-1201.

31. Singh S, Fumery M, Sandborn WJ, Murad MH. Systematic review with network meta-analysis: first- and second-line pharmacotherapy for moderate-severe ulcerative colitis. Aliment Pharmacol Ther 2018;47:162-175.

32. Bonovas S, Lytras T, Nikolopoulos G, Peyrin-Biroulet L, Danese S. Systematic review with network meta-analysis: comparative assessment of tofacitinib and biological therapies for moderate-tosevere ulcerative colitis. Aliment Pharmacol Ther 2018;47:454-465.

33. Feagan BG, Rutgeerts P, Sands BE, et al. GEMINI 1 Study Group. Vedolizumab as induction and maintenance therapy for ulcerative colitis. N Engl J Med 2013;369:699-710.

34. Feagan BG, Rubin DT, Danese S, et al. Efficacy of vedolizumab induction and maintenance therapy in patients with ulcerative colitis, regardless of prior exposure to tumor necrosis factor antagonists. Clin Gastroenterol Hepatol 2017;15:229-239.

35. Sandborn WJ, van Assche G, Reinisch W, et al. Adalimumab induces and maintains clinical remission in patients with moderate-tosevere ulcerative colitis. Gastroenterology 2012;142:257-265.e1-3.
36. Panés J, Rubin DT, Vermeire S, et al. Maintenance of quality of life improvement in a phase 3 study of tofacitinib for patients with moderately to severely active ulcerative colitis. Gut 2017;66 A121-A122.

37. Peyrin-Biroulet L, Sandborn W, Sands BE, et al. Selecting therapeutic targets in inflammatory bowel disease (STRIDE): determining therapeutic goals for treat-to-target. Am J Gastroenterol 2015;110:1324-1338.

38. Kawalec P, Mikrut A, Wiśniewska N, Pilc A. The effectiveness of tofacitinib, a novel Janus kinase inhibitor, in the treatment of rheumatoid arthritis: a systematic review and meta-analysis. Clin Rheumatol 2013;32:1415-1424.

39. Food and drug administration FDA summary review of regulatory action. Tofacitinib for the treatment of rheumatoid athritis. Available from: https://www.accessdata.fda.gov/drugsatfda_docs/ nda/2012/203214Orig1s000SumR.pdf

40. Wollenhaupt J, Silverfield J, Lee EB, et al. Safety and efficacy of tofacitinib, an oral janus kinase inhibitor, for the treatment of rheumatoid arthritis in open-label, longterm extension studies. J Rheumatol 2014;41:837-852.

41. Yamanaka H, Tanaka Y, Takeuchi T, et al. Tofacitinib, an oral Janus kinase inhibitor, as monotherapy or with background methotrexate, in Japanese patients with rheumatoid arthritis: an open-label, longterm extension study. Arthritis Res Ther 2016;18:34.

42. Vieira MC, Zwillich SH, Jansen JP, Smiechowski B, Spurden D, Wallenstein GV. Tofacitinib versus biologic treatments in patients with active rheumatoid arthritis who have had an inadequate response to tumor necrosis factor inhibitors: results from a network meta-analysis. Clin Ther 2016;38:2628-2641.

43. Strand V, Ahadieh S, French J, et al. Systematic review and metaanalysis of serious infections with tofacitinib and biologic diseasemodifying antirheumatic drug treatment in rheumatoid arthritis clinical trials. Arthritis Res Ther 2015;17:362.

44. Vavricka SR, Bentele N, Scharl M, et al. Swiss IBDnet and Swiss IBD Cohort Study Group. Systematic assessment of factors influencing preferences of Crohn's disease patients in selecting an anti-tumor necrosis factor agent (CHOOSE TNF TRIAL). Inflamm Bowel Dis 2012;18:1523-1530.

45. Pfizer. Long-term study of CP-690,550 in subjects with ulcerative colitis (OCTAVE). Available from: https://clinicaltrials.gov/ct2/ show/NCT01470612 [Accessed April 17, 2018].

46. Panaccione R, Ghosh S, Middleton S, et al. Combination therapy with infliximab and azathioprine is superior to monotherapy with either agent in ulcerative colitis. Gastroenterology 2014;146:392-400. 